\title{
44363 - PREOPERATIVE INSULIN RESISTANCE, POSTOP COMPLICATIONS PRELIMINARY FINDINGS
}

\author{
Hema Bagry, McGill University Department of Anesthesia, Montreal, QC, Canada; \\ Gabriele Baldini, McGill University Department of Anesthesia; \\ James Hanley, McGill University, Department of Epidemiology; \\ F Carli, McGill University Department of Anesthesia;
}

INTRODUCTION: Insulin resistance is a clinical entity recognized in the non-diabetic surgical patient, and either in presence or not of hyperglycemia, it can be associated with adverse outcomes. The present study was set up to identify whether a preoperative state of insulin resistance in non diabetic patients undergoing major elective surgical procedures would influence postoperative complication rate.

METHODS: Local IRB approval was obtained for this study. Two-hundred and five adult nondiabetic consecutive patients scheduled for major elective operation (thoracic, abdominal, pelvic and major lower limb joint) were studied. A blood sample was taken in the preoperative clinic to measure fasting plasma glucose and insulin and assess state of insulin resistance using the Homeostasis Model Assesment (HOMA) score[1]. Homa $<1.45$ is considered insulin sensitive, values between 1.46 and 2.49 borderline and > 2.50 insulin resistant. The number and types of postoperative complications and their therapeutic consequences during the fist 30 postoperative days were recorded and classified using the well validated Clavien classification.[2]

RESULTS: Metabolic syndrome was present in $26 \%$ of the patients studied, and particularly in joints $(48 \%)$ and abdominal (30\%). There were $47 \%$ in the sensitive group, $28 \%$ in the borderline group and $25 \%$ in the insulin resistant group. While plasma glucose was similar in the groups (mean 5.2 \pm 0.8 ), insulin was higher in the joints (75 \pm 45$)$, followed by thoracic (61 \pm 40$)$, abdominal (47 \pm 29$)$ and pelvic (45 \pm 20$)$. Approximately $30 \%$ of all patients had postoperative complications. Fourteen out of 51 patients $(28 \%)$ who were insulin resistant before surgery had complications, compared with $15 \%$ in the borderline group and $9 \%$ in the sensitive group.

\begin{tabular}{|c|c|c|c|c|c|}
\hline Variable & All & Thoracic & Abdominal & Pelvic & Joints \\
\hline Patients (N) & 205 & 47 & 56 & 37 & 65 \\
\hline $\begin{array}{l}\text { Preoperative } \\
\text { HOMA } \\
1.46-2.49 \\
\text { N (\%) }\end{array}$ & $58(28)$ & $14(30)$ & $16(29)$ & $9(24)$ & $19(29)$ \\
\hline $\begin{array}{l}\text { Preoperative } \\
\text { HOMA }>2.5 \\
\text { N (\%) }\end{array}$ & $51(25)$ & $13(28)$ & $8(14)$ & $5(14)$ & $25(38)$ \\
\hline $\begin{array}{c}\text { Complications } \\
\text { Yes/No }\end{array}$ & $73 / 132$ & $18 / 29$ & $30 / 26$ & $7 / 30$ & $18 / 47$ \\
\hline $\begin{array}{c}\text { Clavien }>3 \\
(\mathrm{~N})\end{array}$ & 23 & 9 & 10 & 2 & 2 \\
\hline
\end{tabular}


DISCUSSION: These preliminary findings indicate that insulin resistance is common in patients undergoing major surgery and can be a factor responsible for postoperative complications.

Further work is needed to elucidate the trajectory of insulin resistance during the peri-operative period.

REFERENCES:

1. Diabetologia 1985; 28: 412-9

2. Ann Surg 2004; 240: 205-13 